\title{
O sentido do rito e a perda do sagrado na biomedicina: uma reflexão sobre a sóciomagia na saúde pública
}

\author{
Carlos Alberto Borges da Silva ${ }^{1} \&$ Maria da Penha Vasconcellos ${ }^{2}$
}

1. Universidade Estadual de Roraima. Rua sete de Setembro, no 231, Bairro: Canarinho, CEP: 69306-530 Boa Vista, Roraima, Brasil. E-mail: carlosborges@usp.br.

2-. Universidade de São Paulo, Faculdade de Saúde Pública. Av. Dr. Arnaldo,715 CEP. 01246-904 São Paulo, SP. Email: vascon@usp.br

Recebido em : 28/01/2013. Aceito em: 01/03/2013.

\section{RESUMO}

A proposta aqui é examinar os pressupostos mais gerais que caracterizam em termos antropológicos a carreira médica, que de certa forma orienta não só o savoir faire da profissão, como os horizontes cognitivos definidores da ciência da saúde de acordo com padrão da prática médica. Esse exercício compreensivo tem a intenção de deslindar a prática médica como parte da matriz racional predominante no ocidente desde o Iluminismo, e a maneira como ela foi se distanciando da chamada medicina popular ou sóciomagia.

PALAVRAS-CHAVE: Ritos, Biomedicina, Sóciomagia, Saúde Pública

\begin{abstract}
The proposal here is to examine the most general presuppositions than they characterize in anthropological terms the medical career, that in a certain manner guides not only the savoir faire of the profession, as the cognitive horizons that define the science of the health inside of the pattern of the medical practice. That understanding exercise has the intention of extricating the medical practice as part of the predominant rational head office in the occident from Illuminism, and the way like her was if distancing of the call popular medicine or sociomagic.
\end{abstract}

KEY WORDS: Rites, Biomedicine, Sociomagic, Public Health .

\section{INTRODUÇÃO}

Presente em toda a humanidade, o rito sagrado expressa a densa complexidade da condição humana: nos mistérios de Elêusis, nas cerimônias xamanísticas da sociedade Hamatsa, nos costumes dadivosos dos Haussa, na unidade mística religiosa afro-brasileiro, na inflicção cerimoniosa islâmica, no caráter solene das preces cristãs, na contemplação divina budista, perfazendo uma variedade de práticas, ontologicamente criadora do mundo dos símbolos. Sua natureza cosmogônica orienta o lugar do gênero humano diante do universo, criando um "ponto fixo para evitar o caos e a relatividade do espaço profano" (Eliade 2011: 26).

Tanto quando os praticados nos silêncios da intimidade singular ou no clamor entusiástico das reuniões religiosas públicas, os ritos sagrados não se esgotam num fluxo temporal determinado e nem se esvaziam numa circunscrição espacial demarcada. Incluídos na ordem do transcendente por dar significação à realidade, são forças anódinas poderosas, capazes de ultrapassar as infinitas órbitas desenhadas das biografias pessoais, e se esvaírem incólumes por porosidades cheias de representações, para formarem unidades imaginárias contra a imperatividade do caos, numa ordem estranha a toda lógica.

A inescapável finitude da vida humana, as agonias delirantes da existência, os percalços da experiência dos empreendimentos coletivos, as infindáveis aflições que assolam impiedosas, entibiando vorazes a força do corpo físico, formam a substância dos ritos sagrados e proporcionam a epopeia dos mitos e a dramaticidade das crenças, acontecimentos significados cujas estruturas irão dar ossaturas à realidade fissurada, justificando e enfrentando as misteriosas forças contrárias à vida.

O mito, o rito e a crença são então dimensões abissais do sagrado e do profano $^{1}$, recursos

\footnotetext{
${ }^{1}$ Para Durkheim há uma relação simbiótica entre sagrado e profano, que se expressam pela crença e pelos ritos. São duas dimensões que não podem ser separadas, sendo a primeira uma forma de pensamento, a segunda, de ação (Parsons 2010).
} 
simbólicos acionados para negar a mortalidade pela transmortalidade desdobrada na imortalidade (Morin 1975). Por isso, o aparato mitológico-mágico emergido no homo sapiens para arrostar a morte através de ritos fúnebres, embora traduza uma crise, é a sua superação pela esperança e consolação depois da angústia e dilaceração diante do fim da vida. $\mathrm{O}$ homem não só recusa a morte como a rejeita e a vence pelo mito e magia, tentando superar, assim, a catastrófica ideia de aniquilamento (Idem, ibidem). O rito fúnebre caracterizar-se-ia, nesse caso, como um sagrado recurso simbolizado, uma resposta à inevitável nulificação da vida humana $^{2}$. O restabelecimento do equilíbrio por essa definição socialmente objetiva e fatalista é a aceitação da contida perecibilidade da existência, prova inquestionável do sentido da ação humana, tomando de empréstimo essa linguagem weberiana.

Mas a efervescência do conhecimento proporcionada pela razão fez germinar formas audaciosas de pensamento criadas pelo cogito cartesiano. Somadas às utopias das Luzes e à alvorada da ciência e das técnicas, elas vão empurrar para um exílio polar toda forma de pensamento fora de sua indiscutível chancela. Nas suas infindáveis e múltiplas variações, os ritos sagrados, a partir de então, foram condenados a uma espécie rudimentar de experiência cognitiva.

\section{A Razão e a Deslugarização do Sagrado}

Historicamente marcado por raízes que remontam à antiguidade, período de difícil separação entre a medicina dos homens e a cura divina, o rito sagrado destacou-se naquele momento de constituição da história primordial da medicina com a concepção de desvio moral de saúde acionado pela ação de seres sobrenaturais. Este pressuposto irá atravessar séculos até consistir a figura do feiticeiro como intermediário entre o mundo das coisas terrenas e o mundo sagrado, cuja especialização veio instituir o papel do sacerdote, permanecendo, não obstante, a concepção da doença relacionada a certos atributos divinos (Cabral1958). As escolas médicas de Cnido e de Cós, fundada por Hipócrates, deram início ao sistema naturalístico que avançou até Galeno, atribuindo causas naturais à doença, embora persistissem as explicações sobrenaturais até a Idade Média, mesmo diante do surgimento de importantes escolas médicas nesse período (Backes 2009). Embora o pensamento religioso católico nessa época tenha passado a classificar outras formas de pensamento místico como desvios da fé, os santos milagreiros tornar-se-ão referências para curas e malefícios, substancializando uma forma de terapêutica de base teológica, só mudada com a influência do pensamento filosófico e as conquistas da ciência e da técnica nos séculos XVII e XVIII (Freidson 1971).

$\mathrm{O}$ uso de maquinarias gerou uma revolução sem paralelo na produção econômica, expandindo as fronteiras do planeta na velocidade do lucro $\mathrm{e}$ ganhos rápidos. $\mathrm{A}$ imposição devastadora dessa força econômica jamais vista dissolveu todas as relações sociais antigas (Marx 1848). Sob a égide da cinese do progresso, tomada agora no sentido comtiano, tais transformações provocaram alterações profundas na forma de viver, pensar e existir. Não se estranha, mesmo aclamada como conhecimento independente desde a Grécia Antiga, a filosofia deixar de ser um empreendimento distinto das conquistas da ciência (Giddens 1998). A revolução tecnológica impôs mudanças em todos os setores da vida social, submetendo os eventos, considerados inadequados aos seus cânones científicos, às profundezas penumbrosas das experiências cognitivas, doravante lugar das superstições, crendices e toda forma de pensamento sobrenatural.

Esse paradigma de sociedade, no final da segunda metade do século XIX, assume uma feição positivista, inspirada na teoria da evolução social spenceriana e revolucionará a abordagem sobre a natureza ao colocar no topo da evolução social a matriz de desenvolvimento industrial ocidental. As sociedades situadas na base desse desenvolvimento eram consideradas dominadas por constelações de deuses e espíritos selváticos, tidos como pálidas figuras hipostasiadas. Esvaziado de seu conteúdo êmico pela preponderância do pensamento científico, o rito sagrado passou a integrar um campo subjacente a ser costurado e desfeito em suas ações intencionais, para, depois de se tornarem simulacros estereotipados da ciência verdadeira, novamente ser amarrado e juntado aos fragmentos, sendo outras vezes

\footnotetext{
${ }^{2}$ ARIÈS (1981: 12) relata o quanto era tida como desagradável e desonrosa a mors repentina na Idade Média, justamente por ela não ser celebrada ritualmente.
} 
desentrelaçadas até se tornarem protagonistas de um conhecimento caricatural. Não mais podendo ser um tecido permanente, como as urdiduras dos textos proustianos, lembradas por Benjamin (1994), o rito sagrado torna-se parte de uma região da consciência social cuja essência será sempre colocada entre parênteses; simulacro de um conhecimento verdadeiro, esvaído de indiscutíveis princípios, como o da verificação sugerido por Schlick (1972), doravante ferramenta para a eliminação de tudo aquilo desprovido de explicação referenciada pela cognição positiva.

Com isso, as sociedades tradicionais, cujo lugar do sagrado perpassa suas rotinas diárias, passaram a ser chamadas de pré-modernas em alusão à sua limitada capacidade de produção material. À esteira desse processo, o indivíduo dessacralizado deixou de ser visto como membro de um ethos social específico, de uma fratria, clã ou tribo, para ser amalgamado numa humanidade universalmente secularizada, suscetível a monitoramento central, controle social, existencial e fisiológico, protagonistas importantes para o modelo de reprodução e maximização do capital, imprescindível no novo mundo a ser descortinado.

\section{De um Mundo Desencantado para uma Ciência Encantada: O Percurso da Negação da Sóciomagia}

Antevendo a força instrumentalizadora desse processo, sobretudo pelo triunfo da razão sobre a fé, Weber (1944), nos primórdios do século $X X$, vislumbrou ser a secularização da realidade essa prisão de ferro à qual os indivíduos teriam de se submeter. Modelo de desenvolvimento este que, não obstante a racionalidade a ele inerente, somada à necessidade permanente de reprodução do capital e à universalização comercial cada vez mais impessoal, gerou uma negação crescente do sentido mítico e religioso do mundo. Sua prevalência sobre todas as outras formas de sociedade, ainda segundo Weber, passou a disciplinar a maioria das relações sociais, vinculando-as ao triunfo da ciência e à mecanização da vida social pelas mãos de "especialistas sem espírito, sensualistas sem coração, nulidades que imaginam ter atingido um nível de civilização nunca antes alcançado" (Idem, 2003: 135). Especialistas os quais passaram a monitorar e a controlar o corpo, utilizando-se dos domínios do chamado modelo da ciência médica que, contudo as críticas por suas consequências, destacou-se pelas melhorias das expectativas e qualidade de vida em algumas regiões da Europa e Estados Unidos, praticamente erradicando doenças milenares e mortíferas, geradoras de pandemias e endemias das mais variadas, em nome de um modelo ideal de saúde pública, cujos inegáveis avanços na saúde pública, em sua maioria, devem ser atribuídos não só ao poder da medicina moderna, mas também ao conhecimento e especialização das descobertas das causas biológicas das doenças. No entanto, à esteira desse percurso, o bem-estar do cidadão passou a estar relacionado a uma boa disposição física e intelectual, visando à qualidade e à quantidade da produção material do Estado-nação, indicador de seu nível de prosperidade e crescimento econômico, embora com alarmantes consequências no mundo do trabalho ${ }^{3}$, revelador de um conteúdo terrivelmente perverso, como demonstrou Weber.

O cortejo desses vícios impôs-se com rigor sobre o corpo, empurrando-o para uma máquina de poder, esquadrinhando-o, desarticulando-o e recompondo-o por um processo social disciplinatório intenso, passagem decisiva para novas formas de poder (Foucault 2002) ${ }^{4}$. Por meio delas, passou-se a aperfeiçoar as condições de vida das pessoas nas cidades e nas áreas rurais, através de técnicas rápidas e eficazes de intervenção direta e indireta na vida social, quando a medicina transforma-se numa ferramenta importante de disciplinamento e privatização do corpo. Os disputados espetáculos de torturas e execuções públicas foram substituídos pela eliminação da dor física e intervenção especializada, punindo e corrigindo seus desvios pela imposição de metas dietéticas a serem seguidas em torno do ideal estético do corpo saudável (MarzanoParisoli 2004), tornando-o individualizado e misantropo, permanente vigiado.

Dentre outras ações de disciplinamento da

\footnotetext{
${ }^{3}$ Drulhe (1996: 239) citando como fonte um organismo federal americano de saúde, o National Institute for Occupational Safety and Health, indica que 400.000 trabalhadores americanos contraem doença do trabalho, e um quarto desse total perde a vida, algo equivalente à perda de uma guerra do Vietnan.

${ }^{4}$ Embora convincente em termos sociológicos, só para matizar com mais rigor o assunto, é importante a leitura de Giddens (1998) sobre essa abordagem foucaultiana (ver, principalmente, as recomendações constantes nas páginas 319-323)
} 
vida social, os sistemas de abastecimentos de água e saneamento foram expandidos para assegurar saúde à população. Estradas, vias férreas, divisão espacial da cidade e moradias padronizadas, hospitais e centros de medicamentos, no dizer de Foucault (Idem), foram criados para protegê-la contra doenças. Com os mesmos objetivos, abatedouros, produção de alimentos, criação de prisões, asilos e centros de medicina legal foram instituídos como estruturas importantes de saúde pública. Partes da tendência cada vez mais persistente de controle da vida individual e social, na qual a figura do especialista assume papel principal, de indiscutível infalibilidade. $\mathrm{O}$ impacto desse padrão disciplinatório sobre a medicina tornou-a ferramenta restrita ao domínio médico, cuja formação, geralmente longa e extenuante, objetiva reorientar os desequilíbrios do corpo físico e redefinir todos os comportamentos considerados anômalos, como a possessão, o crime e demais anomias das sociedades modernas, em termos da medicina instrumental.

É de se perguntar se não existiria nas sociedades ocidentais o propósito de controle social subjacente a esse ideal de formação profissional do médico. Parsons (1967) especula, por exemplo, que o objetivo dos hospitais psiquiátricos é serem espécies de guardiões do indivíduo em favor da sociedade, quando a cura é impossível ou muito cara, ou mesmo para proteger o paciente dele mesmo ou a sociedade do doente. Nesse caminho está a ideia de ressocializar o doente para os papéis sociais assumidos depois da hospitalização, ressocializando-o novamente se a doença persistir. Assim, não ficam dúvidas do poder disciplinatório dessa revolução da vida social; uma vez universalmente estabelecido gerou vínculos permanentes em todos os setores da realidade, limpando e higienizando, controlando e dissolvendo as formas tradicionais de vida de acordo com o ideal cosmopolita de sociedade. Nesse percurso de higienização e controle, as chamadas práticas mágico-religiosas foram sistematicamente relegadas a um plano periférico, místico ou religioso, eufemisticamente considerado medicina popular, portanto reduzido às práticas informais de não especialistas.

Porém é de indagar, apesar da preponderância desse modelo terapêutico sobre todas as outras práticas curativas, quais as linhas de fronteira efetivamente separadoras entre essas duas práticas, uma vez ser a medicina popular frequentemente praticada? Uma resposta viável vem de Laplantine (1991), ao asseverar não existir uma prática terapêutica exclusivamente científica ou tão só mágicoreligiosa. No seu ponto de vista, as práticas terapêuticas populares perpassam e até mesmo se correlacionam com o universo da medicina oficial. Isso aponta serem as diferenças entre as duas medicinas apenas de grau, equivalente às diferenças entre cores, não percebida por quem sofre de daltonismo, como disse Ackerknecht (1985).

O problema é que o saber científico, segundo Lévi-Strauss (1989), por ser posterior a essa forma de conhecimento, sempre teve no saber, dito mágico, uma maneira embrionária de ciência, não o percebendo como um sistema bem articulado; independente da forma como se constitui a ciência. Diz o autor: em vez de opor magia e ciência, seria melhor colocá-las em paralelo, como dois modos de conhecimento desiguais quanto a resultados teóricos e práticos, mas não em relação às operações mentais supostas por ambas. Numa leitura equivalente, Laplantine (Idem), opondose a prevalência do modelo biomédico no tratamento das doenças, diz ser ele o responsável pela dualização do campo do conhecimento, por separar de um lado o empírico e, de outro, o simbólico, como duas leituras dicotômicas irreconciliáveis. A verdade é que nos horizontes dos profissionais de saúde em geral, o modelo biomédico, ao enfatizar a negação do modelo sóciomágico, no caso, o simbólico, acaba não alcançando a maneira como as pessoas operacionam as diversas formas de explicação aos abalos do estado de normalidade do corpo.

\section{O Corpo Desritualizado na Prática Médica}

Mas será mesmo necessária a vinculação entre essas terapêuticas? Isto é: a cura inexoravelmente tem projeções que adentram o campo simbólico? A resposta poderia ser sim, se conjeturasse que vários fatores da prática médica indicam sua ritualização, embora a maioria dos médicos pense o contrário. O simples fato de os hospitais, ambulatórios e consultórios médicos se caracterizarem como espaços de manipulação do corpo, impõe determinadas ritualizações na prática médica. A separação entre o limpo e o sujo, o puro e o impuro, vida e morte, saúde e doença, até na 
própria disposição espacial no interior dos hospitais, no qual a UTI tem mais relação com a morte se comparado aos berçários e enfermarias, sugere a presença de aspectos simbolizados.

Porém, desde o início da vida universitária, é persistente na formação médica a eliminação da simbologia do corpo. Os ritos de iniciação do jovem estudante de medicina submetido ao contato com morte nos necrotérios em aulas práticas de anatomia evidenciam um ritual de afastamento do medo da morte, em nome de sua vulgarização e dessimbolização. Ao mesmo tempo, ao coisificá-lo, dissecá-lo e deserotizalo, o estudante de medicina aprende a materializá-lo; e separado em glândulas, humores e funções, e não tendo nem pensamentos e batimentos cardíacos, entendese o corpo desprovido e desconectado da alma.

A cientificidade inerente à formação médica, geralmente longa e extenuante, ao procurar banir os aspectos simbólicos que envolvem o corpo para sua total dessacralização, seguindo os argumentos de Carriburu e Ménoret (Carricaburu \& Ménoret 2004), traz como revés a contribuição para a reprodução e produção de uma sociedade de classe. Isso se daria porque a medicina industrial, que se desenvolveu com a utilização crescente da ciência biológica e de suas técnicas, engendra uma lógica de especialização geradora de uma hierarquização no interior da própria medicina. Como consequência, isso imporia uma hierarquização interna da disciplina, que também fabricaria uma hierarquização dos serviços, dos profissionais e do recrutamento sem igual de doentes. Com isso se teria um especialista médico envolvido com altíssima tecnologia e uma medicina de massa, cuja especialização decorre de sua atividade prática, colocada numa relação de importância inferior à primeira.

Também o fato de o médico ser o único profissional a lidar com os momentos do nascimento e da morte, do início e do fim da vida, duas fases da existência humana socialmente ritualizada, faz dele algo inabalavelmente transcendente aos homens comuns, explicando esses profissionais serem chamados de doutores, uma importante base de status profissional (Freidson 1971). Vendo-se como um quase Deus, para quem o corpo do paciente é desprovido de qualquer linguagem humana, o médico o percebe como um mero amontoado de órgãos (Le Breton 1993). Consoante a Parsons (1967), esse é o motivo da relação médico-paciente se definir por uma institucionalização de procedimentos morais que prescreve ao médico o bem-estar de seus pacientes em lugar de seus interesses de ordem individual. Orientado pelo conhecimento dado em sua formação científica, o desempenho de seu papel socialmente legitimado, definir-se-ia assim pela identificação da doença e sua posterior cura, uma ação totalmente instrumentalizada sobre o corpo.

Outro aspecto dessa relação é a posição do paciente ou do doente, de total submissão à cientificidade da especialidade médica. Ao paciente, devido ao seu estado de saúde, não tendo outra opção como reação, cabe apenas sustentar o saber médico através de motivações positivas, como a convicção de que o saber (ou poder) médico o curará. Por conta disso, ainda segundo Parsons (Idem), a relação entre médico e paciente será totalmente esvaziada de conteúdos morais não se configurando no afiançamento de qualquer aproximação de contento social, pois na visão solipsista do médico, o doente necessita unicamente de seus conhecimentos especializados. Todo seu grupo social e as pessoas de seu entorno encontrar-se-ão obstados e impossibilitados de reagir ou dar solução à enfermidade. Somente diante de credenciais médicas, legitimadas por instituições universitárias e associações de aglomeração profissional em medicina, o conhecimento sobre a doença será reconhecido legitimamente, negando ao doente a compreensão situacional de sua enfermidade.

Tais fatores implicam num distanciamento abissal entre médico e paciente: o primeiro estará diretamente vinculado à ideia da cura da doença trazida em um corpo-portador; o segundo, alguém sem reação a ela, o doente, ou o paciente, assim chamado por esperar e aguardar, totalmente submisso. Esse paradigma se instituiu pelo esvaziamento de qualquer ambiguidade por parte do doente, diante da imperatividade do saber médico. Qualquer contestação a lhe ser imposta, pressuporia a estigmatização social (Goffman 1963) do papel do médico, e o consequente rebaixamento de seu status social, projetando-o para mais próximo da medicina de massa ou mesmo das práticas sócio mágicas.

\section{CONCLUSÃO}


O problema suscitado sobre a negação dos aspectos simbólicos em torno da doença pode assim ser colocado: embora a cura médica cumpra a função primordial de reestabelecer a ordem perdida pelo corpo físico, em decorrência da doença, ela não aciona nenhuma significação simbolizada pelo fato de não haver a implicação de rituais. O simples reestabelecimento da saúde física após a intervenção biomédica, não completa por si só a quebra da ordem imposta pela doença, pelo simples fato de a significação simbólica não ter sido mobilizada no ato da cura médica, por ser ela exclusivamente orgânica. Se a dimensão simbólica é apartada do corpo, ele será sua negação, um não-corpo, um objeto inanimado desprovido de humanidade.

O corpo, por ser parte de uma ordem moral social está, portanto, inserido numa ordem maior, o mundo. Daí a impossibilidade de separá-lo do mundo, pois a alteração em um, consequentemente provocará alteração em outro; são nexos de significação pelos quais estão ligadas nossas experiências individuais e coletivas. Assim, todos os objetos de um sistema têm o indivíduo como fabricador de significados e símbolos compartilhados, dando sentido e legitimidade ao conjunto das relações sociais.

Por fim, evidencia-se por essa reflexão, que a experiência da doença, não obstante a preponderância do modelo biomédico é também negociada em termos mágicos e religiosos, que perfazem variadas formas terapêuticas, muitas vezes como único auxílio médico possível, invariavelmente modelado por diferentes itinerários de cura. Fica a sugestão de que o viés antropológico poderá ser definidor para repensar muitos dos padrões de saúde e doença, por entender que as duas importantes dimensões da enfermidade, a vida social e a pessoal, estarão intrinsicamente relacionadas por serem fenômenos multidimensionais e multifacetados.

\section{AGRADECIMENTOS}

À FAPESP, processo 2011/02123-7, e a CAPES, processo 1544-11-0, por financiarem, em nível de Pós-doutorado junto à Faculdade de Saúde Pública da USP, o projeto de pesquisa intitulado Terapêuticas de Cura Sóciomágicas em Boa Vista (RR) e em Portugal.

\section{REFERÊNCIAS BIBLIOGRÁFICAS}

Ackerknecht, E. H. 1985. Medicina y antropologia social: estudios varios. Madrid, Akal Editor.

Ariès, Ph. 1981. O homem diante da morte. V.1, RJ., F. Alves.

Backes, M. T. S. \& al. 2009. Conceitos de saúde e doença ao longo da história sob olhar epidemiológico e antropológico. Revista de Enfermagem, UERJ, Rio de Janeiro, jan/mar; 17(1):111-7.

Benjamin, W.1994. Magia e técnica, arte e politica: ensaios sobre literatura e história da cultura. São Paulo, Brasiliense.

Cabral, O. 1958. A medicina teológica e as benzeduras: suas raízes na história e sua persistência no folclore. Revista do Arquivo Municipal, separata $\mathrm{n}^{\circ}$ CLX, Departamento de Cultura.

Carricaburu, D. \& Ménoret, M. 2004. Sociologie de la santé: institutions, professions et maladies. Paris, Armand Colin.

Cros, M. (org). 1996. Les maux de l'autre: la maladie comme objet anthropologique. Paris, L'Harmattan.

Drulhe, M. 1996. Santé et Societé: le façonnement sociétal de la santé. Paris, Press Universitaire de France.

Freidson, E. 1971, Profession of medicine. NY, Dodd, Mead \& Company.

Foucault, M. 1987. Vigiar e Punir: história da violência nas prisões. $26^{\mathrm{a}}$.ed.Petrópolis, Vozes.

Geertz, C. 1978. A interpretação das culturas. Rio de Janeiro, Zahar Editores.

Giddens, A. 1998. Política, sociologia e teoria social: encontros com o pensamento social clássico contemporâneo. São Paulo, Editora da UNESP.

Goffman, E. 1963. Stigma: notes on the managment of spiled identity. NY, Simon and Schuster.

Laplantine, F. 1991. Antropologia da doença. São Paulo, Martins Fontes.

Le Breton, D. 1993. La chair à vif: Unsages médicaux et mondains du corp humain. Paris, Métailié.

1996. Anthropologie des usages médicaux du corps humain, In: CROS, Michèle (org) Les maux de l'autre: la maladie comme objet anthropologique. Paris,L'Harmattan.

Levi-Strauss, C. 1989. O Pensamento Selvagem. Campinas, Papirus.

Marx, K. 1848. Manifesto Comunista, (versão em pdf).

Morin, E. 1975. O enigma do homem.: para uma nova Antropologia. RJ., Zahar.

Parsons, T. 1967. Sociological Theory and Modern Society New York, Free Press.

2010. A estrutura da ação social: um estudo de teoria social com especial referência a um grupo de autores europeus recentes. Vol. 1, Petrópolis, Vozes. 
Sampaio, G. R. 2001. Nas trincheiras da cura: as diferentes medicinas no Rio de Janeiro Imperial. Campinas, Editora da UNICAMP.

Schlick, M. 1972. Science: conjectures and refutation. Conjectures and refutation, London.

Weber, M. 1944. Economia y Sociedad, I e II. México, Fundo de Cultura Economia.

2003. A Ética Protestante e o Espírito do

Capitalismo. São Paulo, Martin Claret. 